DOI 10. 18307/2022. 0102

(C) 2022 by Journal of Lake Sciences

\title{
巢湖蓝藻水华监测预警与模拟分析平台设计与实践”
}

\author{
邱银国 ${ }^{1}$, 段洪涛 ${ }^{* * *}$, 万能胜 ${ }^{2}$, 高 芮 $^{2}$, 黄佳聪 ${ }^{1}$, 薛 坤 $^{1}$, 彭兆亮 ${ }^{1}$, 肖鹏峰 ${ }^{3}$ \\ (1: 中国科学院南京地理与湖泊研究所,南京 210008) \\ (2: 安徽省巢湖管理局湖泊生态环境研究院,合肥 230000) \\ (3: 南京大学地理与海洋科学学院,南京 210023)
}

\begin{abstract}
摘 要: 近 20 年来, 巢湖蓝藻水华频繁暴发, 对流域内居民生活和社会生产产生了严重影响. 由于缺乏蓝藻水华全方位 监测、高精度模拟和智能化分析手段,传统方法难以实现 “现状掌握、异常识别、原因追溯、未来模拟” 的目标, 无法满足巢 湖蓝藻水华科学防控与应急处置的要求, 蓝藻水华引起的突发事件随时可能发生. 本文针对巢湖蓝藻水华的全面监测和 应急决策问题,整合了卫星遥感、无人机监测、视频监控、浮标监测和人工巡测手段,构建了巢湖水质和水华全方位监测 网络; 结合巢湖水动力一水质一藻类耦合模拟模型, 研制了蓝藻水华预测预警和蓝藻水华暴发应急处置模块, 实现了蓝藻 水华短期 (未来 2 日逐时) 和长期 (未来 7 日逐日) 模拟,并实现了未来 5 日蓝藻水华沿岸堆积模拟. 最终,通过集成巢湖 水质和水华监测、预测预警、应急处置等模块, 研发了巢湖蓝藻水华监测预警与模拟分析平台, 实现了全湖水质和水华现 状迅速掌握、超标信息自动识别与高精度预测预警、沿岸重点区域水华堆积风险评估等功能,为巢湖蓝藻水华的科学防 控和应急处置提供了科学依据和数据支撑.
\end{abstract}

关键词: 蓝藻水华;立体监测;预测预警;决策支撑;巢湖

\section{Design and practice of a platform for monitoring, early-warning and simulation of algal blooms in Lake Chaohu*}

Qiu Yinguo $^{1}$, Duan Hongtao ${ }^{1 * *}$, Wan Nengsheng ${ }^{2}$, Gao Rui ${ }^{2}$, Huang Jiacong ${ }^{1}$, Xue Kun ${ }^{1}$, Peng Zhaoliang ${ }^{1} \&$ Xiao Pengfeng ${ }^{3}$

(1: Nanjing Institute of Geography and Limnology, Chinese Academy of Sciences, Nanjing 210008, P.R.China)

(2: Institute of Lake Ecology and Environment, Anhui Provincial Lake Chaohu Administration, Hefei 230000, P.R. China)

(3: School of Geography and Ocean Science, Nanjing University, Nanjing 210023, P.R.China)

Abstract: Algal blooms occur frequently in Lake Chaohu in recent 20 years, producing a serious impact on the resident life and social production in Lake Chaohu watershed. Due to the lack of effective means in terms of comprehensive monitoring, high-precision simulation, and intelligent analysis, it is quite difficult for traditional methods to achieve the goal of status mastering, anomalies identifying, causes tracing, and trend simulating of water quality and algal blooms. Accordingly, the requirements of scientific prevention and emergency disposal of algal blooms in Lake Chaohu cannot be satisfied currently, and emergencies caused by algal blooms may occur at any time. Aiming at the requirements of comprehensive monitoring and emergency decision-making of algal blooms, a comprehensive monitoring network of water quality and algal blooms has been established in Lake Chaohu, by integrating several monitoring means, i.e., satellite remote sensing, UAV ( unmanned aerial vehicle) monitoring, video monitoring, buoy and field monitoring. And modules of prediction, early-warning and emergency response of algal blooms are developed by combining the coupled hydrodynamic-water quality-algal blooms model. And both short-term ( hourly in the next 2 days) and long-term ( daily in the next 7 days) simulations of algal blooms are realized, as well as the simulation of algal blooms accumulation along the coast in

* 2021-06-02 收稿;2021-07-14 收修改稿.

国家水体污染控制与治理科技重大专项 (2017ZX07603-001)、国家自然科学基金项目 (42101433) 和江苏省自然科 学基金项目 (BK20201100) 联合资助.

** 通信作者;E-mail: htduan@ niglas.ac.cn. 
the next 5 days. Finally, a platform for monitoring, early-warning and simulation of algal blooms in Lake Chaohu has been developed by integrating several function modules, e.g., monitoring of water quality and algal blooms, prediction and early-warning, emergency response, etc. By running this platform, the present situation, exceding standard limits information, and high-precision simulation and prediction of water quality and algae bloom in the whole lake can be grasped quickly and automatically, and risk assessment of algae bloom accumulation in key areas along the coast can also be realized. It shows that the implemented platform can provide scientific basis and data support for scientific prevention and emergency disposal of algal blooms in Lake Chaohu.

Keywords: Algal blooms; stereo monitoring; prediction and early warning; decision support; Lake Chaohu

巢湖 ( $31^{\circ} 25^{\prime} 28^{\prime \prime} \sim 31^{\circ} 43^{\prime} 28^{\prime \prime} \mathrm{N}, 117^{\circ} 16^{\prime} 54^{\prime \prime} \sim 117^{\circ} 51^{\prime} 46^{\prime \prime} \mathrm{E}$ ) 位于安徽省中部合肥市境内, 水域面积约 780 $\mathrm{km}^{2}$, 东西长约 $54.5 \mathrm{~km}$, 南北长约 $21 \mathrm{~km}$, 平均水深约 $3 \mathrm{~m}^{[1-3]}$. 巢湖是我国五大淡水湖之一, 也是我国富营养 化重点治理的“三湖”之一 ${ }^{[4-6]}$, 具有供水、防洪、灌溉、渔业、旅游等多种服务功能 ${ }^{[7]}$. 巢湖共有人湖河流 33 条,其中主要出入湖河流有 10 条,包括南淝河、十五里河、派河、杭埠河、柘臬河、烔炀河、双桥河、兆河、白石 天河、裕溪河 ${ }^{[8]}$. 近年来, 随着流域内人口的快速增长以及工农业生产的快速发展, 巢湖水体营养水平居高 不下 ${ }^{[9-11]}$, 导致蓝藻水华频发, 对流域内居民的生产生活、生命健康都产生了很大影响,已经成为制约区域社 会经济可持续发展的重大问题 ${ }^{[12-13]}$. 一方面,巢湖现有的蓝藻水华监测手段不完善,主要依靠卫星遥感和人 工监测手段获取全湖蓝藻水华现状信息 ${ }^{[14-17]}$, 监测结果的时空分辨率不高, 不能实现 “整个湖区一重点区域 一关键位置” 全覆盖的水质和水华现状信息快速获取及超标信息及时识别; 另一方面, 已有的巢湖蓝藻水华 模拟与分析方法通常以日为单位对全湖蓝藻水华的演变趋势进行模拟预测, 存在自动化与智能化水平低、 结果精度和可靠性差等不足, 模拟预测结果与巢湖蓝藻水华的应急防控需求脱节, 导致巢湖蓝藻水华的时 空演变趋势 (特别是高时空分辨率的变化信息)、分区水华风险等级、重点区域水华堆积风险与持续时长等 关键信息获取困难,难以为水华暴发期的应急处置提供科学、有效的决策支撑.

本文围绕巢湖蓝藻水华现状快速掌握、时空演变趋势高精度模拟及应急决策支撑, 尝试整合卫星遥感、 无人机监测、视频监控、浮标监测、人工巡测和数值模拟等手段, 突破蓝藻水华全方位监控和高精度模拟等 关键技术, 构建巢湖蓝藻水华监测预警与模拟分析平台, 及时掌握全湖水质、水华现状情况和超标信息, 实 现全湖蓝藻水华模拟预测与风险评估、重点区域水华堆积风险研判、不同预警等级下的应急预案优选, 为巢 湖蓝藻水华的科学防控提供决策支撑, 最大程度降低蓝藻水华产生的危害, 保障巢湖生态系统健康和水源 地水质安全.

\section{1 平台总体设计}

\section{1 蓝藻水华“天一空一地”立体监测模式设计}

传统巢湖蓝藻水华监测工作主要依靠卫星遥感和人工巡测手段, 在监测效率、监测结果的全面性和数 据时效性等方面都存在很大不足: (1) 卫星遥感手段受云雨天气影响较大, 全年有一半以上日期没有有效的 影像数据 ${ }^{[12]}$, 无法获取全湖蓝藻水华信息; (2) 国控断面和常规监测站点每月 1 次人工监测, 蓝藻监测站点 每周 2 次人工监测, 监测的时间频率偏低, 在蓝藻水华暴发期不能迅速掌握全湖水质和水华现状信息, 难以 满足巢湖蓝藻水华应急防控的需求. 针对上述问题, 设计了巢湖蓝藻水华 “天一空一地”立体监测模式 (表 1), 在传统监测手段的基础上,补充无人机、岸基视频、浮标等手段, 实现 “整个湖区一重点区域一关键位置” 全覆盖的水质和水华“天一空一地”一体化监测, 及时掌握全湖水质、水华现状分布和超标报警信息, 为巢湖 蓝藻水华的科学管理和应急防控服务. 更为详细的内容见参考文献 [12].

巢湖蓝藻水华“天一空一地”立体监测模式中,水质、水华监测手段可分为常规监测手段和应急监测手段 两类. 常规监测手段包括卫星遥感、视频监控、浮标监测和人工巡测 , 无需人工干预、定时自动启动; 应急监 测手段包括无人机监测和人工巡测, 在蓝藻水华暴发、水质/水华超标报警等应急情况下根据水华应急防控 要求按需启动, 对重点区域、关键位置的水华/水质状况进行加密监测. 针对不同的监测手段设计了数据处 理与超标报警流程 (图 1): 针对 “天一空一地” 立体监测获取的遥感影像、数字图像、视频文件和水质参数数 据, 设计影像数据蓝藻水华提取与水质参数反演、图像数据蓝藻水华提取与统计分析、视频数据蓝藻水华提 取与统计分析、水质监测数据时空建模与分析等方法, 迅速掌握全湖水质和水华现状; 设定超标报警阈值, 
实现水质、水华超标信息的智能识别; 根据监测手段的不同,实现超标信息的自动报警 (卫星遥感、视频监 控、浮标监测 $)$ 和人工报警 (无人机监测、人工巡测).

表 1 巢湖蓝藻水华立体监测模式

Tab.1 Stereo monitoring model of algal blooms in Lake Chaohu

\begin{tabular}{|c|c|c|c|c|}
\hline 监测区域 & 覆盖范围 & 监测手段和指标 & 监测频率 & 启动条件 \\
\hline 整个湖区 & 巢湖水域范围 & $\begin{array}{l}\text { 卫星遥感: 蓝藻水华面积、叶绿素 } a \\
\text { 浓度 }\end{array}$ & $\begin{array}{l}1 \text { 次/d( 无云雨天气条 } \\
\text { 件) }\end{array}$ & 每日定时 \\
\hline 重点区域 & $\begin{array}{l}\text { 主要环湖河流 } \\
\text { 人湖口、景观 } \\
\text { 区、蓝藻水华易 } \\
\text { 暴发区 }\end{array}$ & $\begin{array}{l}\text { (1)卫星遥感: 蓝藻水华面积、叶绿素 } a \\
\text { 浓度; 2无人机监测: 蓝藻水华空间分 } \\
\text { 布范围、面积、强度; 3)视频监控: 蓝藻 } \\
\text { 水华空间分布范围、比例、强度 }\end{array}$ & $\begin{array}{l}\text { 卫星遥感: } 1 \text { 次/d (无 } \\
\text { 云雨天气条件); (2)无 } \\
\text { 人机监测 : 根据应急 } \\
\text { 决策方案动态调整; } \\
\text { (3)视频监控: } 1 \text { 次/ } h \\
(8: 00-18: 00)\end{array}$ & $\begin{array}{l}\text { (1)卫星遥感:每日定 } \\
\text { 时; (2)无人机监测: } \\
\text { 根据水华应急防控 } \\
\text { 要求确定; (3)视频监 } \\
\text { 控:每日定时 }\end{array}$ \\
\hline 关键位置 & $\begin{array}{l}\text { 取水口、国/省 } \\
\text { 控断面、滨岸带 } \\
\text { 水华易 堆 积 } \\
\text { 区域 }\end{array}$ & $\begin{array}{l}\text { (1)视频监控: 蓝藻水华空间分布范围、 } \\
\text { 比例、强度; 浮标监测、人工巡测 : 总 } \\
\text { 氮、总磷、氨氮、化学需氧量、高锰酸盐 } \\
\text { 指数、水温、叶绿素 } a \text { 、溶解氧、pH 值、 } \\
\text { 电导率、生化需氧量 }\end{array}$ & $\begin{array}{l}\text { 视 频 监 控: } 1 \text { 次/h } \\
(8: 00-18: 00) ;(2) \text { 浮 } \\
\text { 标 监测: } 1 \text { 次 } / 4 \mathrm{~h} \text {; } \\
\text { (3) 巡测: } 1 \text { 次/月 }\end{array}$ & $\begin{array}{l}\text { (1)视频监控: 每日定 } \\
\text { 时; (2)浮标监测: 每 } \\
\text { 日定时; (3)人工巡 } \\
\text { 测: 每月定时、根据 } \\
\text { 水华应急防控要求 } \\
\text { 确定 }\end{array}$ \\
\hline
\end{tabular}

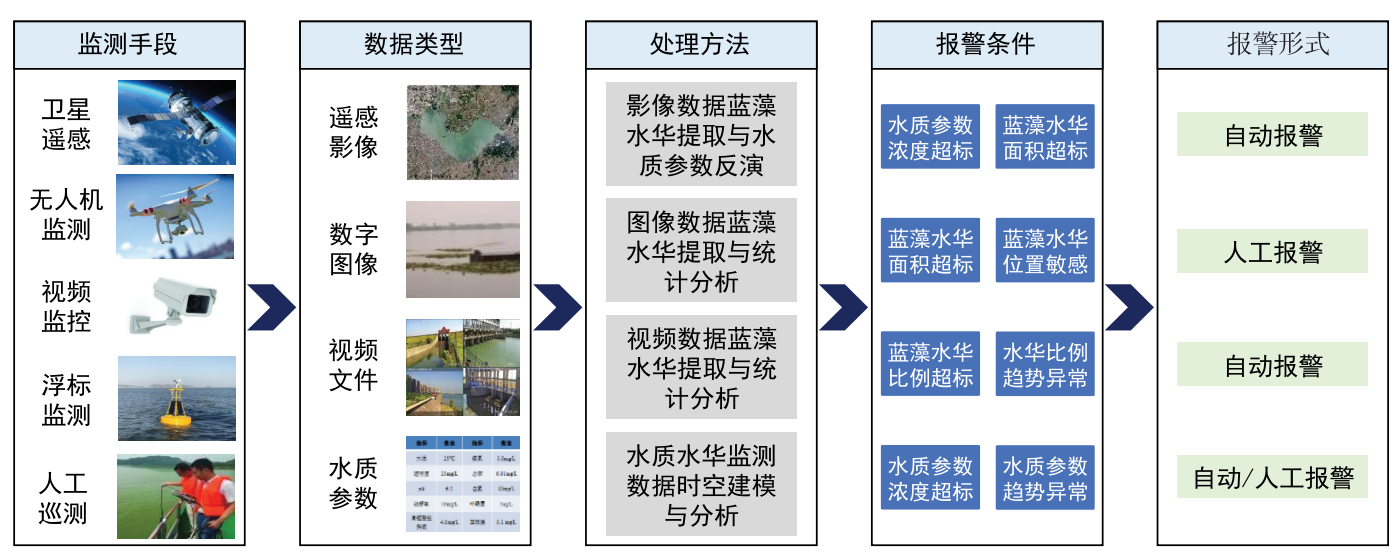

图 1 巢湖蓝藻水华协同监测数据处理流程

Fig.1 Processing flow of stereo monitoring data of algal blooms in Lake Chaohu

\section{2 平台体系结构设计}

巢湖蓝藻水华监测预警与模拟分析平台的体系结构包括 3 层: 数据获取层、业务逻辑层与应用表现层 (图 2).

(1)数据获取层: 为系统业务功能的实现、模型计算等提供必要的数据支撑. 整合“天一空一地”一体化 监测获取的多源监测数据以及水文、气象、流场、水生态等模型驱动数据, 通过构建不同类型数据的统一存 储与整编方式、数据规范以及人库标准, 实现多源异构数据的标准化处理, 最终建成巢湖蓝藻水华监测预警 与模拟分析平台标准化时空数据库.

(2) 业务逻辑层: 是连接平台数据库与人机交互界面的关键,包括数据处理模块、模拟分析模块和智能 决策模块. 其中, 数据处理模块基于 “天一空一地”一体化监测数据进行水质和水华现状提取与超标分析, 并 基于平台综合数据库建设成果针对各业务模型进行驱动数据组装; 模拟分析模块通过集成水质数据超标智 能识别、蓝藻水华监测和预警等业务模型, 实现巢湖水质/水华超标信息的自动识别、蓝藻水华演变态势高 
精度模拟和风险评估; 智能决策模块基于数据处理模块和模拟分析模块的计算结果实现湖区水质和水华超 标判断、短/长期模拟预测、风险评估与应急处置模拟等功能, 为巢湖蓝藻水华的监测、预警和应对提供决策 支撑.

（3）应用表现层: 是整个平台的功能出口, 通过基于 Web Services 服务架构的人机界面访问接口, 实现 平台中各个功能模块的前端可视化展示与人机交互,包括水质和水华现状、异常、趋势、风险等级、应急预案 等,为巢湖流域的综合管理提供决策支持.



图 2 巢湖蓝藻水华监测预警与模拟分析平台体系结构

Fig.2 Architecture of monitoring-early warning-simulation analysis platform for algal blooms in Lake Chaohu

\section{2 关键技术研究}

\section{1 基于多源卫星遥感的全湖蓝藻水华全自动提取关键技术}

卫星遥感具有快速获取大区域影像数据的优势, 结合遥感影像数据处理方法可以在晴好天气条件下迅 速获取全湖范围的蓝藻水华空间分布信息 ${ }^{[18-20]}$. 然而,传统方法需要经过 “数据下载一数据处理一结果上传” 过程,且该过程需要人工参与、耗时较长,难以实现当日全湖蓝藻水华信息的快速获取,在全湖蓝藻水华监 测的效率方面存在很大的不足.

为了解决基于卫星遥感监测的全湖蓝藻水华提取时效性问题, 本文设计并实现了一种针对 Terra/Aqua MODIS、Sentinel-2 MSI、GOCI 等多源卫星数据的巢湖蓝藻水华全自动提取方法, 无需人工干预即可自动获取 当日巢湖全湖蓝藻水华现状信息. 共包含 3 个模块 (图 3a) : (1) 影像数据自动下载模块: 研发了多源卫星影 像数据下载程序和定时任务管理程序, 并将二者分别封装为独立运行程序; 研发了控制子模块, 通过调度定 时任务管理程序驱动影像数据下载程序; 在影像数据下载程序运行结束后, 通过控制子模块向蓝藻水华自 动提取模块发送启动指令; (2) 蓝藻水华自动提取模块: 研制了针对不同类型影像数据的蓝藻水华提取算法 
(图 3b), 并将二者分别封装为独立运行程序; 研发了控制子模块, 在接收到影像数据自动下载模块发送的 启动指令后, 启动蓝藻水华提取程序和水质参数反演程序对影像数据进行处理, 在处理结束后向统计分析 与自动发布模块发送启动指令; (3) 统计分析与自动发布模块: 设计蓝藻水华分区统计程序和数据批量发布 程序, 并将二者分别封装为独立运行程序; 研发了控制子模块, 在接收到蓝藻水华自动提取模块发送的启动 指令后, 启动蓝藻水华分区统计程序和数据批量发布程序, 定量评价不同湖区的蓝藻水华情况, 并将卫星影 像原图以及蓝藻水华提取结果自动发布、批量人库.

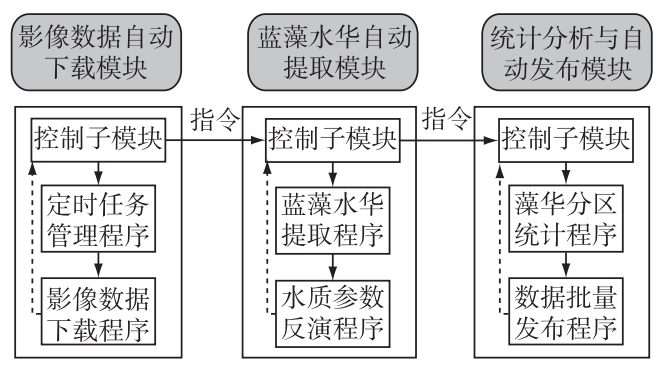

(a) 蓝藻水华卫星遥感全自动监测功能模块
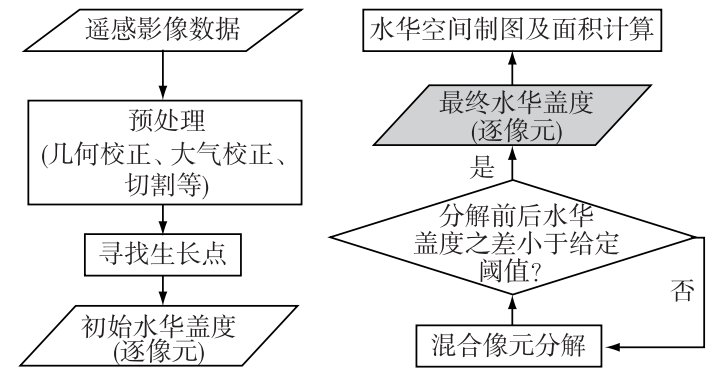

(b) 遥感影像数据蓝藻水华提取算法原理

图 3 基于多源卫星数据的巢湖蓝藻水华自动提取方法

Fig.3 Automatic extraction of algal blooms in Lake Chaohu based on multisource satellites data

\section{2 基于岸基视频的滨岸带蓝藻水华信息高精度提取算法}

蓝藻水华发生后, 容易在滨岸带堆积发臭, 消耗大量水体溶解氧, 甚至造成水生生物死亡, 形成次生灾 害 $^{[21]}$, 对周围居民生活产生严重影响,甚至威胁城市饮用水源地安全, 阻碍区域可持续发展 ${ }^{[22]}$. 因此, 如何 及时掌握滨岸带的蓝藻水华时空分布情况, 对于湖泊蓝藻水华应急防控工作具有重要意义. 然而, 蓝藻水华 具有突发性强、时空演变快等特征, 单纯依靠传统的卫星遥感、人工巡测等手段难以及时、准确掌握整个湖 泊滨岸带的水华空间分布、暴发强度、聚集范围等信息, 导致传统滨岸带蓝藻水华应急处置措施时效性低、 水华及其次生灾害难以得到有效控制.

为了监控非法捕捞等活动, 巢湖沿湖岸线布置了 33 个摄像头, 可以自动调焦和设置观测角度; 相对于 卫星, 可以实现晴好和部分阴雨天 (光线足够) 白天连续观测, 实现了对局部重点区域的有效监控. 本文利用 视频监控设备可以连续工作的优势, 设计了一种针对摄像头图片的蓝藻水华高精度提取算法, 实现了蓝藻 信息的自动提取 (图 4), 并在系统中进行了集成. 主要方案包括: (1) 针对环巢湖岸基视频监控设备,规定了 最佳拍摄角度, 对蓝藻水华信息进行连续监控并定时 (每小时 1 次) 抓取图像, 通过无线传输方式将图像数 据传输至服务器; (2) 利用研发的数字图像蓝藻水华高精度提取算法, 基于视频监控数据进行蓝藻水华关键 信息提取 (时间、地点、水华范围、强度等); (3) 基于各监控点位的蓝藻水华信息提取结果, 通过超标点位报 警、滨岸带水华强度信息实时动态展示等手段,实现巢湖滨岸带蓝藻水华信息的快速掌握.

\section{3 蓝藻水华模拟与堆积风险评估关键技术}

传统湖库蓝藻水华模拟与预测方法主要以日为时间尺度, 模拟预测结果的时间分辨率不高, 在蓝藻水 华及其衍生灾害的应急决策支持方面还存在很大的局限性; 另外,传统方法关注湖区的蓝藻水华整体分布、 面积、强度等信息, 忽略了针对滨岸带重点区域的水华堆积风险与堆积时长模拟, 模拟预测结果与实际的蓝 藻水华防控需求间存在很大程度的脱节. 在此背景下, 本文构建了巢湖蓝藻水华预测模型, 实现了蓝藻水华 短期 (未来 2 日,逐小时) 和长期 (未来 7 日,逐日) 预测预警; 同时, 对巢湖滨岸带未来 5 日蓝藻水华沿岸堆 积风险进行了逐日模拟评估, 为水源地、景观区等重点区域的蓝藻水华打捞等应急处置提供决策依据.

巢湖蓝藻水华高分辨率模拟与滨岸带堆积风险评估方法 (图 5) 涉及的关键技术环节包括: (1) 利用现 有的巢湖流域水文模型和湖泊水动力模型, 以蓝藻卫星遥感监测结果和浮标监测数据等为初始场, 耦合三 维数字流场动态模拟结果、气象预报数据、闸坝调度规则等, 实现巢湖水动力一水质一藻类的高精度耦合模 拟; (2) 接人未来一周逐小时气象预报数据, 结合三维数字流场、高频水质水文监测数据等, 进行巢湖蓝藻水 


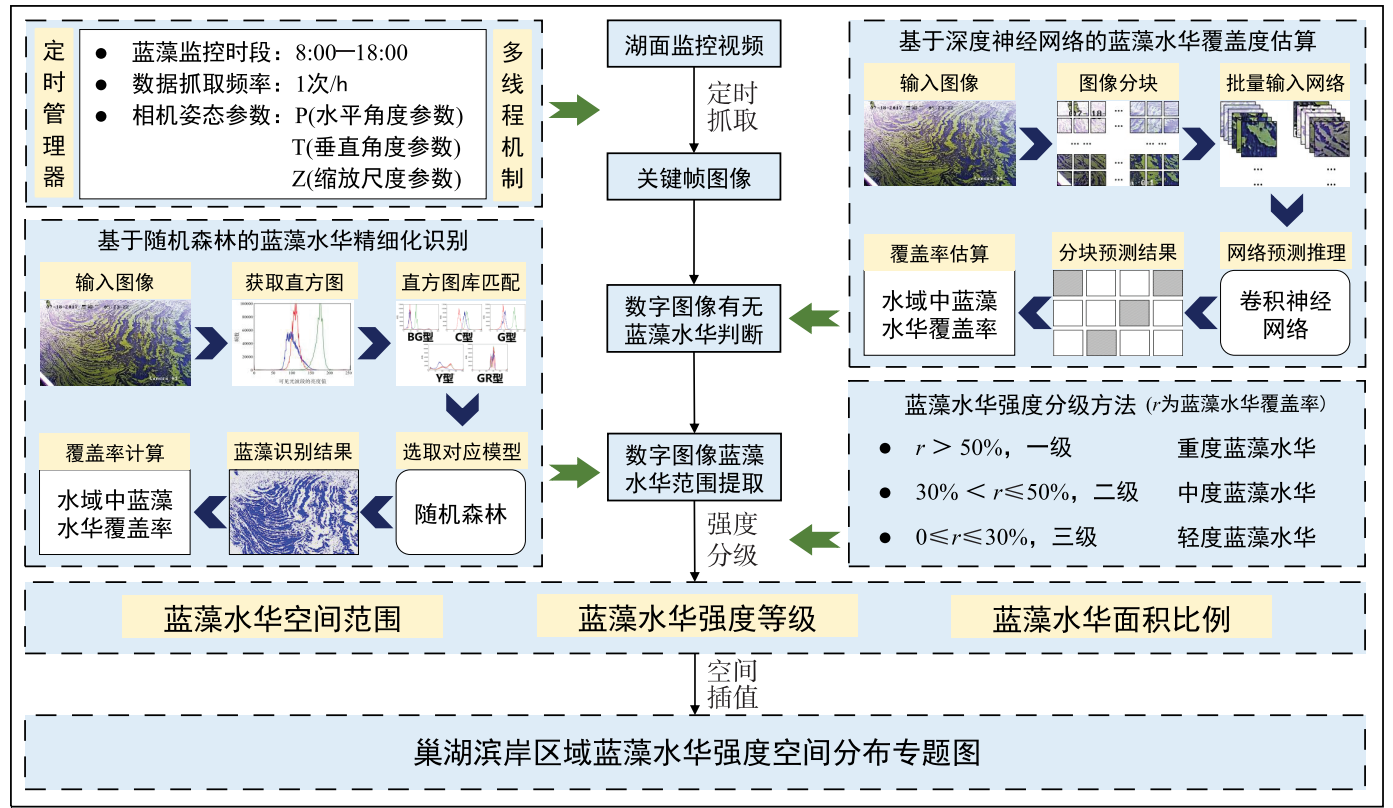

图 4 巢湖滨岸带蓝藻水华现状信息获取方法

Fig.4 Acquisition method of algal blooms status in coastal area of Lake Chaohu

华演变态势高时空分辨率模拟 ${ }^{[23]}$; (3) 基于蓝藻水华未来变化的模拟结果,综合考虑藻类生物量、岸线形 态、湖泊水动力、风速风向等要素, 量化评估巢湖滨岸带的蓝藻水华堆积风险, 实现滨岸带蓝藻水华堆积风 险等级和堆积时长的模拟预测 ${ }^{[24]}$; (4) 研发定时任务管理器, 定时启动巢湖蓝藻水华模拟和滨岸带水华堆 积风险评估模型, 并将模型计算结果进行自动人库与发布, 实现巢湖蓝藻模拟预警全过程的“无人值守”.

\section{3 平台实现与应用}

基于汶览器/服务器 (Brower/Server, B/S) 结构, 实现了巢湖蓝藻水华监测预警与模拟分析平台的全部 功能. 平台共包含 4 大功能模块: (1) “天一空一地”一体化监测模块: 实现不同监测手段获取数据的集成展 示、超标报警和统计分析; (2) 预测预警模块: 实现巢湖蓝藻水华和主要水质参数的模拟和预警,包括短期 (未来 2 日,逐时) 和长期 (未来 7 日,逐日) 预测预警; (3) 应急处置模块: 预测未来 5 日巢湖滨岸带不同区域 的蓝藻水华堆积风险及时空演变趋势, 并提供应急决策支撑; (4) 报告中心模块: 实现巢湖蓝藻水华监测日 报和预测预警周报的查询、展示和下载. 目前, 平台已在安徽省巢湖管理局进行业务化运行, 其中平台运行 文件和数据库系统均部署于合肥市政务云平台.

\section{1 水质和水华“天一空一地”协调监测与分析}

基于卫星遥感、无人机监测、视频监控、浮标监测和人工巡测手段,实现了“整个湖区一重点区域一关键 位置” 全覆盖的巢湖蓝藻水华 “天一空一地”一体化监测, 可以迅速掌握全湖水质和水华的现状分布以及超标 报警信息 (图 6a). 基于设计的蓝藻水华多源卫星遥感自动监测方法, 实现了蓝藻水华全自动提取, 可快速 掌握晴好天气下当日全湖蓝藻水华现状 (图 6b). 基于岸基视频监控(图 6c), 实现了“数据拍摄一蓝藻提取一 结果人库一前端展示” 全过程的“无人值守”, 每日 8:00-18:00 期间每整小时动态更新数据 (图 7). 基于湖 区水质浮标数据, 实现了全湖水质现状、超标信息、变化趋势等信息的快速获取 (图 $6 \mathrm{~d}$, 每 $4 \mathrm{~h}$ 动态更新数 据). 通过不同监测手段的整合, 实现了从全湖到重点区域到关键位置的水质和水华“天一空一地” 立体监测.

\section{2 蓝藻水华模拟预警与应急决策支持}

耦合巢湖水动力一水质一藻类耦合模型, 基于高时空分辨率气象预报数据、巢湖精细化三维数字流场数 


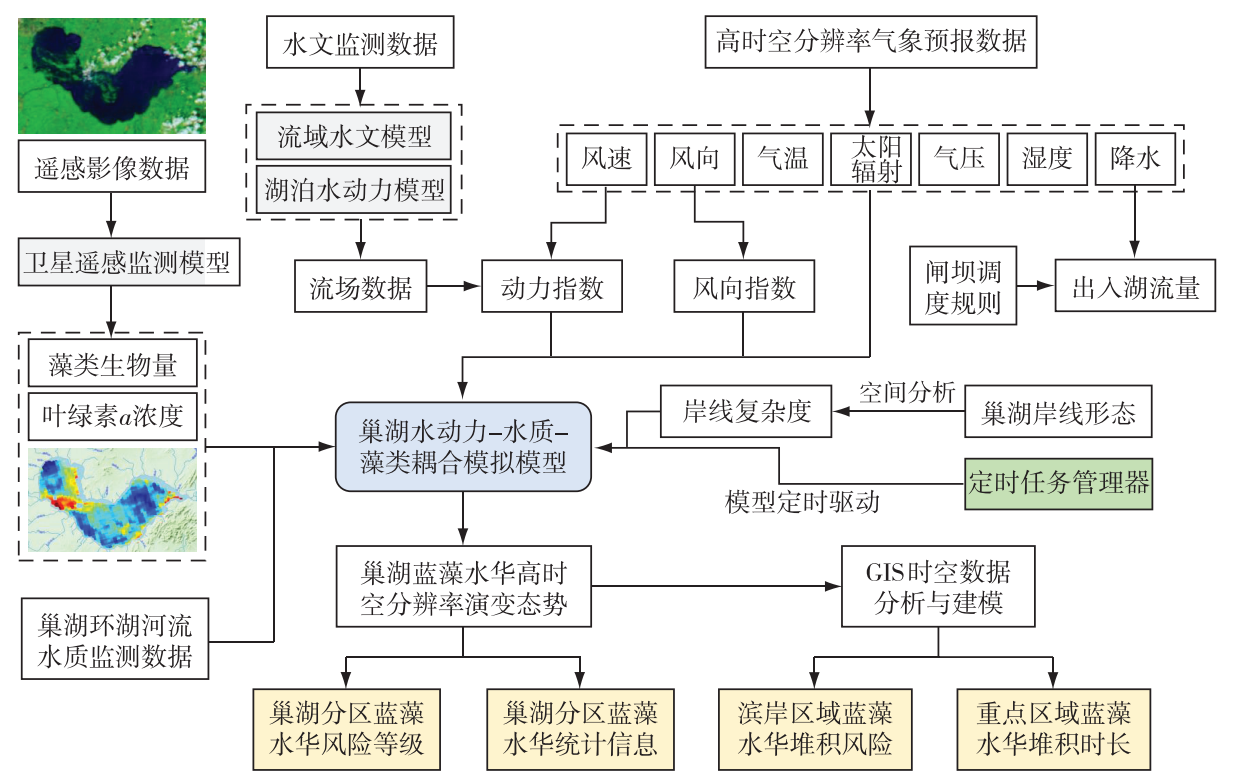

图 5 巢湖蓝藻水华高精度模拟与滨岸带堆积风险评估方法

Fig.5 Method of high-precision simulation of algal blooms in Lake Chaohu and risk assessment of coastal area accumulation

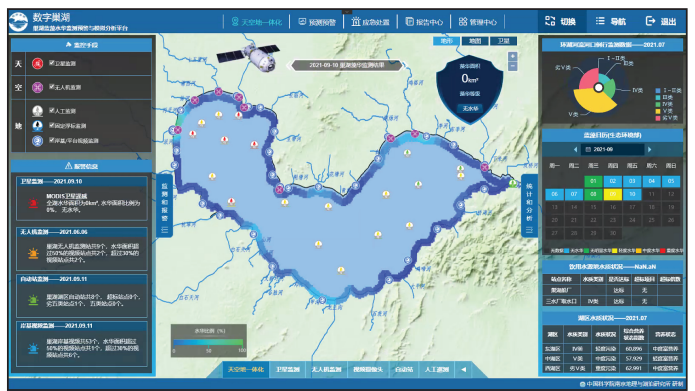

(a) 湖区水质和水华现状及超标信息识别

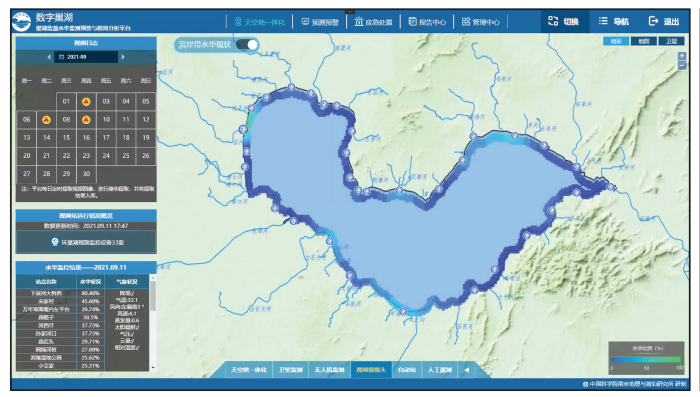

(c) 基于视频监控的巢湖滨岸带水华现状获取

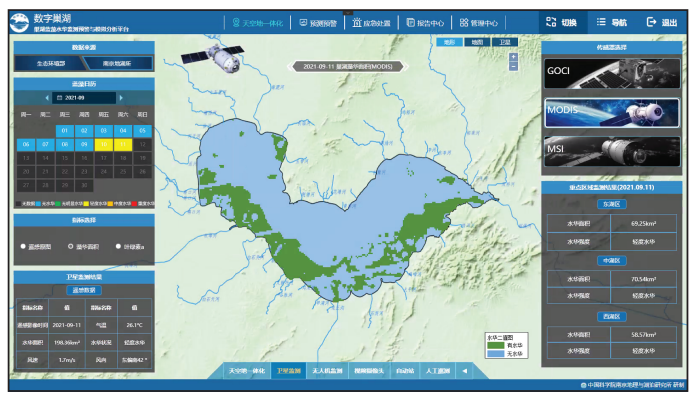

(b) 基于卫星遥感的巢湖蓝藻水华自动监测

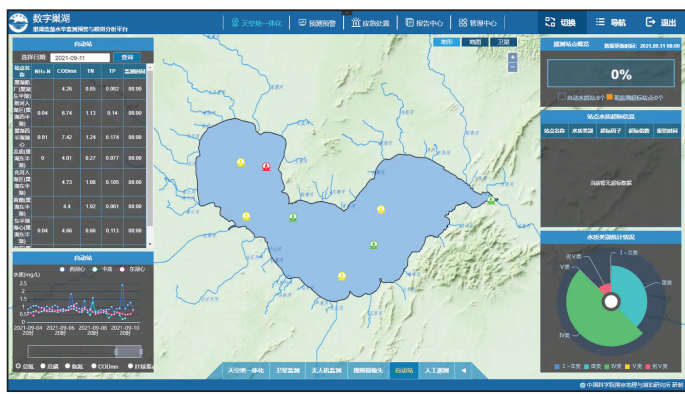

(d) 基于自动浮标的水质监测和统计分析

图 6 “天一空一地”立体监测功能效果

Fig.6 Effect of “space-air-ground” stereo monitoring

据、高频水质水文监测数据等, 实现了巢湖蓝藻水华和主要水质参数的短期 (未来 2 日, 逐时) 和长期 (未来 


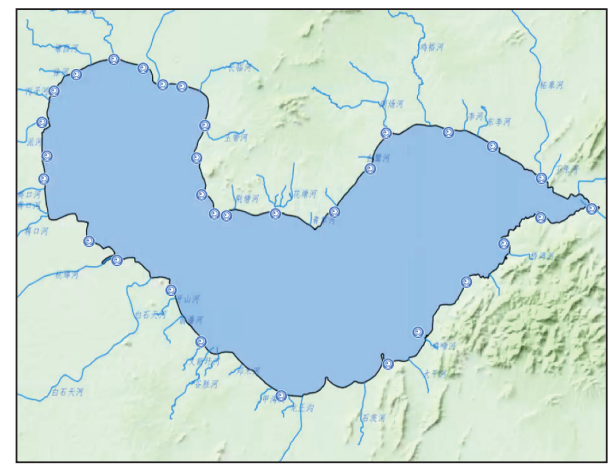

(a) 环巢湖视频监控设备安装点位

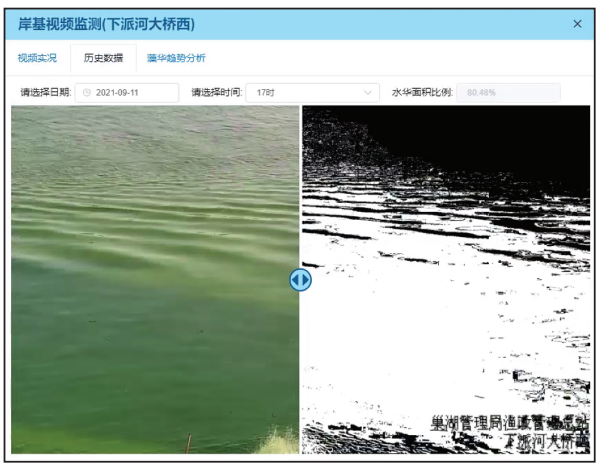

(c) 蓝藻水华监控历史数据查询



(b) 实时视频监控数据

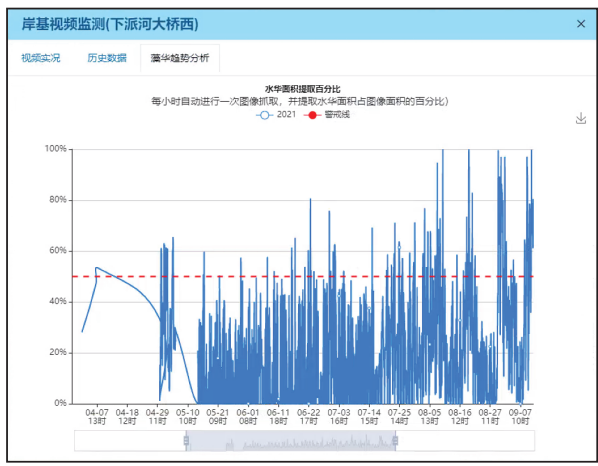

(d) 蓝澡水华强度变化趋势查询

图 7 基于视频监控的巢湖滨岸带蓝藻水华监控功能效果

Fig.7 Algal blooms monitoring results of coastal area of Lake Chaohu based on video

7 日,逐日) 模拟预测. 其中, 模拟指标主要包含总氮、总磷、溶解氧、高锰酸盐指数、叶绿素 $a$ 、表层藻类生物 量、水华概率和氨氮. 同时,顾及巢湖岸线形态和复杂度,实现了对未来 5 日巢湖滨岸带蓝藻水华堆积情况 进行模拟, 能够定量评估滨岸带不同区域水华堆积风险及其时空演变情况; 平台也实现了 3 类常用蓝藻水 华应急处置手段 (打捞、引水、围隔) 的效果模拟, 可以对不同蓝藻水华预警结果下的应急预案进行比较和优 选,对巢湖蓝藻水华应急处置起到了重要支撑作用(图 8).

\section{3 平台性能评估}

为评估平台性能, 对蓝藻水华卫星遥感监测、滨岸带蓝藻水华现状监测、蓝藻水华模拟与预警等关键功 能的实现效率进行了测试 (表 2). 结果表明 (表 3), 平台不同模块响应效率较高, 综合解决能力强, 可以满足 当前巢湖蓝藻水华防控工作的实际需求.

表 2 平台性能测试用服务器配置

Tab.2 Configuration of the server applied for performance test of this platform

\begin{tabular}{ccccc}
\hline 中央处理器 & 内存 & 带宽 & 操作系统 & 硬盘空间 \\
\hline 16 核 & $32 \mathrm{~GB}$ & $8 \mathrm{Mbps}$ & Windows Server 2019 & $2048 \mathrm{~GB}$ \\
\hline
\end{tabular}

\section{4 结语}

本文针对巢湖蓝藻水华的 “天一空一地” 立体监测和应急防控问题,通过整合卫星遥感、无人机监测、视 频监控、浮标监测、人工巡测和数值模拟等手段,构建了 “整个湖区一重点区域一关键位置” 全覆盖的巢湖蓝 藻水华 “天一空一地” 立体监测框架, 实现了全湖水质与蓝藻水华现状、超标、变化趋势等信息的快速获取; 集 


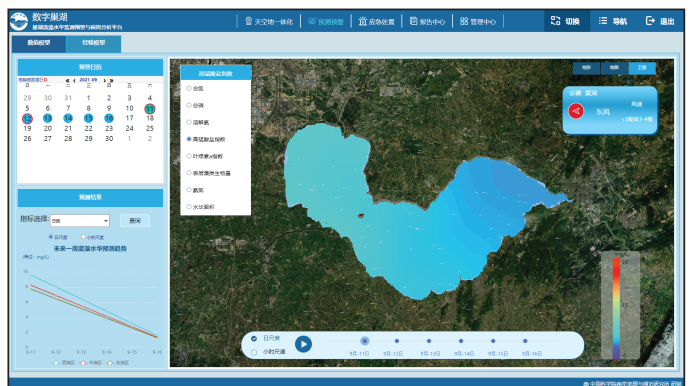

(a) 巢湖蓝藻水华高精度预测预警

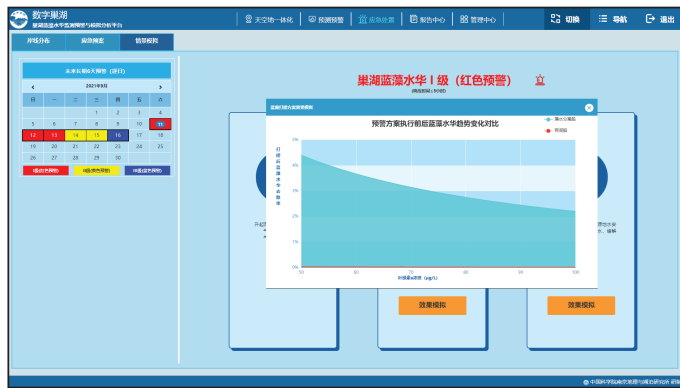

(c) 应急处置措施效果模拟与方案优选

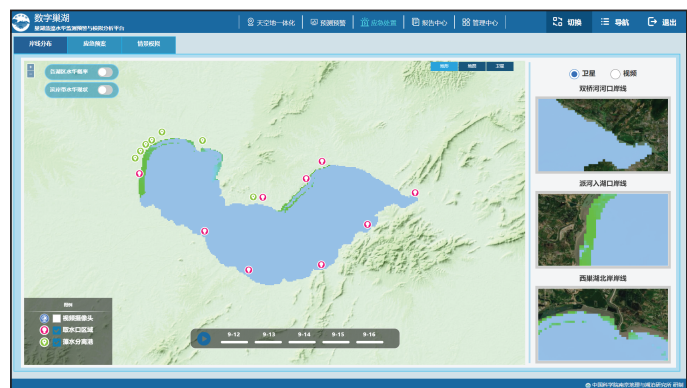

(b) 巢湖滨岸带蓝藻水华堆积风险评估

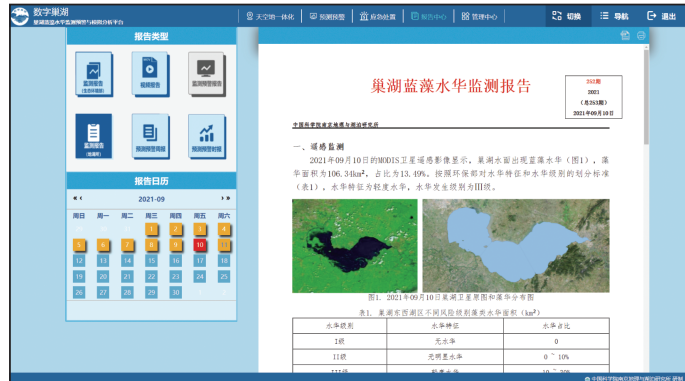

(d) 蓝藻水华监测预警报告动态生成

图 8 巢湖蓝藻水华高精度模拟预警与应急决策支持功能效果

Fig. 8 High precision simulation, early warning and emergent decision support of algal blooms in Lake Chaohu

表 3 平台性能测试结果

Tab.3 Results of performance test of this platform

\begin{tabular}{|c|c|c|c|c|}
\hline 序号 & 功能案例 & 实现耗时 & 模型精度 & 备注 \\
\hline 1 & $\begin{array}{l}\text { 全湖蓝藻水华卫星遥 } \\
\text { 感监测 }\end{array}$ & $176 \min$ & $\begin{array}{l}\text { 蓝藻水华面积提取结果精度:大 } \\
\text { 于 } 80 \% \text { (图 9a) }\end{array}$ & $\begin{array}{l}\text { 包含数据下载、数据处理、结果 } \\
\text { 人库与数据发布 }\end{array}$ \\
\hline 2 & $\begin{array}{l}\text { 基于岸基视频监控设 } \\
\text { 备的滨岸带蓝藻水华 } \\
\text { 现状获取 }\end{array}$ & $12 \mathrm{~min}$ & $\begin{array}{l}\text { 蓝藻水华比例提取结果精度:大 } \\
\text { 于 } 80 \% \text { (图 9b) }\end{array}$ & $\begin{array}{l}\text { 包含环巢湖 } 33 \text { 个视频监控设备 } \\
\text { 抓取图像、图像数据回传与批处 } \\
\text { 理、结果人库与动态空间插值 }\end{array}$ \\
\hline 3 & $\begin{array}{l}\text { 未来 } 1 \text { 周蓝藻水华预 } \\
\text { 测预警 }\end{array}$ & $63 \mathrm{~min}$ & $\begin{array}{l}\text { 概率水华发生概率预测结果精 } \\
\text { 度: 当日大于 } 90 \% \text {, 次 日 大于 } \\
80 \% \text {, 第 } 3 \text { 天大 } 75 \% \text { (图 9c) }\end{array}$ & $\begin{array}{l}\text { 包含短期 (未来 } 2 \text { 日, 逐时) 和长 } \\
\text { 期 (未来 } 7 \text { 日, 逐日) 预测预警 }\end{array}$ \\
\hline 4 & $\begin{array}{l}\text { 未来 } 5 \text { 日滨岸带蓝藻 } \\
\text { 水华堆积风险评估 }\end{array}$ & $48 \mathrm{~min}$ & $\begin{array}{l}\text { 模拟结果与卫星监测结果总体 } \\
\text { 吻合 (图 9d) }\end{array}$ & 未来 5 日 (逐日) 堆积风险评估 \\
\hline 5 & $\begin{array}{l}\text { 巢湖蓝藻水华监测预 } \\
\text { 警报告自动生成 }\end{array}$ & $1.7 \mathrm{~s}$ & - & $\begin{array}{l}\text { 包含巢湖蓝藻水华监测日报和 } \\
\text { 预测预警周报的在线生成 }\end{array}$ \\
\hline
\end{tabular}

成了巢湖水动力一水质一藻类耦合模拟模型, 接人了流域高时空分辨率气象预报数据和高频水质水文监测 数据, 实现了巢湖蓝藻水华和主要水质参数的精细化模拟与实时预测预警, 可为蓝藻水华应急处置提供决 策支撑. 测试结果表明, 平台核心功能实现效率及模型模拟结果精度较高, 能够满足巢湖蓝藻水华监测和防 控工作的实际需求. 随着高性能计算、GIS 时空数据分析、高光谱无人机数据采集和处理、数字孪生等技术的 不断发展, 有望进一步强化其在监测效率、模拟精度、可视化效果等方面的功能, 在富营养化湖泊蓝藻水华 监测预警等方面具有广阔的应用前景. 


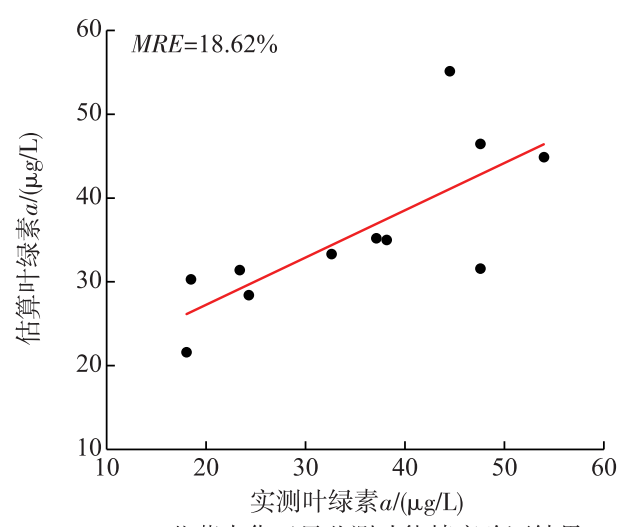

(a) 蓝藻水华卫星监测功能精度验证结果

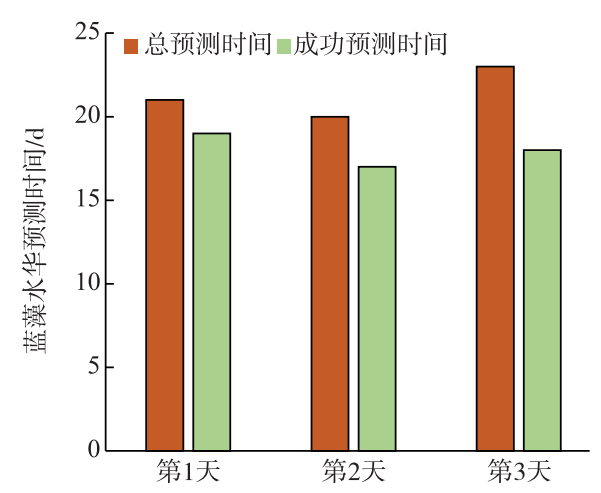

(c) 蓝藻水华预测预警功能精度验证结果

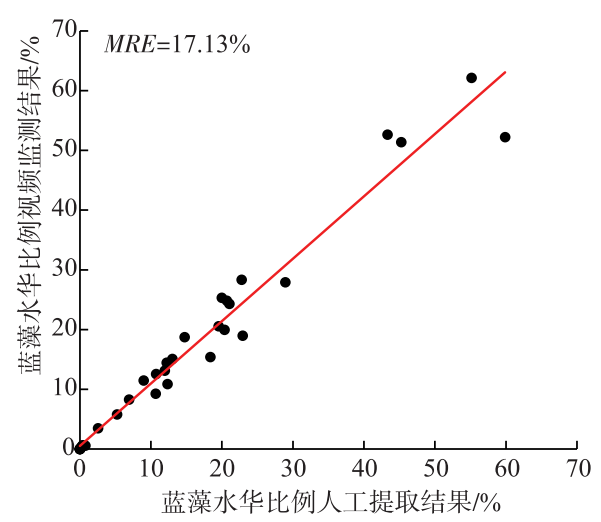

(b) 蓝藻水华强度视频监测功能精度验证结果

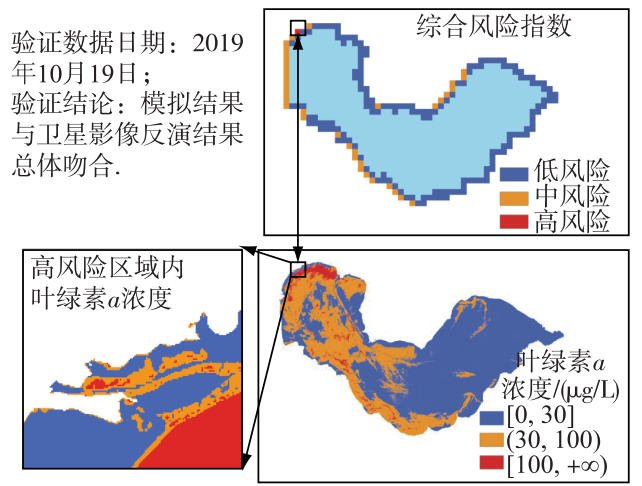

(d) 滨岸带蓝藻水华堆积风险评估功能精度验证结果

图 9 模型精度验证结果

Fig.9 Validation results of precision of model

\section{5 参考文献}

[ 1 ] Qi TC, Xiao QT, Miao YQ et al. Temporal and spatial variation of carbon dioxide concentration and its exchange fluxes in Lake Chaohu. J Lake Sci, 2019, 31(3) : 766-778. DOI: 10.18307/2019.0315. [齐天赐, 肖启涛, 苗雨青等. 巢湖水 体二氧化碳浓度时空分布特征及其水一气交换通量. 湖泊科学, 2019, 31(3) : 766-778. ]

[ 2 ] Guan Y, Zhang M, Yang Z et al. Intra-annual variation and correlations of functional traits in Microcystis and Dolichospermum in Lake Chaohu. Ecological Indicators, 2020, 111: 106052. DOI: 10.1016/j.ecolind.2019.106052.

[ 3 ] Qi GH, Ma XS, He SY et al. Long-term spatiotemporal variation analysis and probability prediction of algal blooms in Lake Chaohu (2009-2018) based on multi-source remote sensing data. J Lake Sci, 2021, 33(2) : 414-427. DOI: 10.18307/ 2021.0204. [祁国华, 马晓双, 何诗瑜等. 基于多源遥感数据的巢湖水华长时序时空变化(2009-2018 年) 分析与 发生概率预测. 湖泊科学, 2021, 33(2): 414-427.]

[ 4 ] Qin N, He W, Liu WX et al. Tissue distribution, bioaccumulation, and carcinogenic risk of polycyclic aromatic hydrocarbons in aquatic organisms from Lake Chaohu, China. Science of the Total Environment, 2020, 749: 141577. DOI: 10. 1016/j.scitotenv.2020.141577.

[ 5 ] Zhu ZQ, Dai YY, Zhang R et al. Occurrence, distribution and partitioning of polychlorinated dibenzothiophenes (PCDTs) in Chaohu Lake, Southeast China. Environmental Pollution, 2021, 277: 116751. DOI: 10.1016/j.envpol.2021.116751.

[ 6 ] Wu ZS, Lai XJ, Li KY. Water quality assessment of rivers in Lake Chaohu Basin (China) using water quality index. Ecological Indicators, 2021, 121: 107021. DOI: 10.1016/j.ecolind.2020.107021.

[ 7 ] Zhang ZM, Gao JF, Yan RH. Assessment of ecosystem services based on aquatic ecoregion of the area surrounding the Chaohu Lake. Resources and Environment in the Yangtze Basin, 2015, 24(7): 1110-1118. [张志明, 高俊峰, 间人华. 基于水生态功能区的巢湖环湖带生态服务功能评价. 长江流域资源与环境, 2015, 24(7): 1110-1118.] 
[ 8 ] Zhang M, Shi XL, Yang Z et al. The variation of water quality from 2012 to 2018 in Lake Chaohu and the mitigating strategy on cyanobacterial blooms. J Lake Sci, 2020, 32(1): 11-20. DOI: 10.18307/2020.0102. [张民, 史小丽, 阳振等. 2012-2018 年巢湖水质变化趋势分析和蓝藻防控建议. 湖泊科学, 2020, 32(1) : 11-20.]

[ 9 ] Liang QC, Zhang YC, Xue K et al. Remote sensing-based estimation for Gaussian distribution parameters of vertical structure of algal biomass in Lake Chaohu. J Lake Sci, 2017, 29(3) : 546-557. DOI: 10.18307/2017.0303. [梁其椿, 张玉 超, 薛坤等. 巢湖藻类高斯垂向分布结构参数的遥感估算. 湖泊科学, 2017, 29(3) : 546-557.]

[10] Duan HT, Tao M, Loiselle SA et al. MODIS observations of cyanobacterial risks in a eutrophic lake: Implications for longterm safety evaluation in drinking-water source. Water Research, 2017, 122: 455-470. DOI: 10.1016/j. watres. 2017. 06.022 .

[11] Li SM, Liu JP, Song KS et al. Analysis on spatial and temporal character of algae bloom in Lake Chaohu and its driving factors based on landsat imagery. Resources and Environment in the Yangtze Basin, 2019, 28(5) : 1205-1213. DOI: 10. 11870/cjlyzyyhj201905020. [李晟铭, 刘吉平, 宋开山等. 基于 Landsat 影像巢湖蓝藻水华暴发时空变化特征及其 驱动因素分析. 长江流域资源与环境, 2019, 28(5): 1205-1213.]

[12] Duan HT, Wan NS, Qiu YG et al. Discussions and practices on the framework of monitoring system in eutrophic lakes and reservoirs. J Lake Sci, 2020, 32(5) : 1396-1405. DOI: 10.18307/2020.0513. [段洪涛, 万能胜, 邱银国等. 富营养化 湖库天-空-地一体化监控平台系统设计与实践. 湖泊科学, 2020, 32(5) : 1396-1405.]

[13] Yin FC, Zhang ZY. Survey of Chaohu Lake eutrophication research. J Lake Sci, 2003, 15(4) : 377-384. DOI: 10.18307/ 2003.0414. [殷福才, 张之源. 巢湖富营养化研究进展. 湖泊科学, 2003, 15(4) : 377-384.]

[14] Mei CQ, Wang XY, Peng P. Application of MODIS data for monitoring blue-green algal bloom in Chaohu Lake. Remote Sensing Technology and Application, 2008, 23(3) : 328-332,241. [梅长青, 王心源, 彭鹏. 应用 MODIS 数据监测巢 湖蓝藻水华的研究. 遥感技术与应用, $2008, \mathbf{2 3}(3): 328-332,241$.

[15] Chen CB, Zhou BT, Tian YZ et al. Application of environmental satellite HJ1A / 1B-CCD data for cyanobacteria dynamic monitoring in Chaohu Lake. Environmental Monitoring in China, 2014, 30(1): 200-204. [陈春波, 周宝同, 田永中等. 环境一号卫星多光谱数据在巢湖蓝藻动态监测中的应用. 中国环境监测 , 2014, 30(1) : 200-204.]

[16] Zhang DY, Yin X, She B et al. Using multi-source satellite imagery data to monitor cyanobacterial blooms of Chaohu Lake. Infrared and Laser Engineering, 2019, 48(7) : 303-314. [张东彦, 尹勋, 余宝等. 多源卫星遥感数据监测巢湖蓝藻 水华爆发研究. 红外与激光工程, 2019, 48(7) : 303-314.]

[17] Chao MC, Zhao Q, Yang TL et al. Remote sensing monitoring and spatiotemporal variation of turbidity of Chaohu Lake based on GF-1 image. Journal of Atmospheric and Environmental Optics, 2021, 16(2): 149-157. [苌明灿, 赵强, 杨铁 利等. 基于 GF-1 影像的巢湖浊度遥感监测及时空变化研究. 大气与环境光学学报, 2021, 16(2): 149-157.]

[18] Ma RH, Zhang YC, Duan HT. The status and development of the non-traditional lake water color remote sensing. $J$ Lake Sci, 2016, 28(2) : 237-245. DOI: 10.18307/2016.0201. [马荣华, 张玉超, 段洪涛. 非传统湖泊水色遥感的现状与 发展. 湖泊科学, 2016, 28(2): 237-245.]

[19] Zhu GW, Shi K, Li W et al. Seasonal forecast method of cyanobacterial bloom intensity in eutrophic Lake Taihu, China. J Lake Sci , 2020, 32 (5) : 1421-1431. DOI：10.18307/2020.0504. [ 朱广伟, 施坤, 李未等. 太湖蓝藻水华的年度情势 预测方法探讨. 湖泊科学, 2020, 32(5) : 1421-1431.]

[20] Chen JQ, Wang J, Wang QW et al. Common fate of sister lakes in Hulunbuir Grassland: Long-term harmful algal bloom crisis from multi-source remote sensing insights. Journal of Hydrology, 2021, 594: 125970. DOI: 10. 1016/j. jhydrol. 2021.125970.

[21] Tang XX, Shen M, Duan HT. Temporal and spatial distribution of algal blooms in Lake Chaohu, 2000-2015. J Lake Sci, 2017, 29(2) : 276-284. DOI: 10.18307/2017.0203. [ 唐晓先, 沈明, 段洪涛. 巢湖蓝藻水华时空分布 (2000-2015 年). 湖泊科学, $2017, \mathbf{2 9}(2): 276-284$. ]

[22] Cai LL, Zhu GW, Liu JW et al. Characteristics and effects on nutrients of algal blooms accumulation and dissipation in littoral zone. China Environmental Science, 2018, 38(8) : 3087-3093. [蔡琳琳, 朱广伟, 刘俊伟等. 滨岸带水华堆积与 消散特征及其营养盐效应. 中国环境科学, 2018, 38(8) : 3087-3093.]

[23] Peng ZL, Hu WP, Liu G et al. Development and evaluation of a real-time forecasting framework for daily water quality forecasts for Lake Chaohu to Lead time of six days. Science of the Total Environment, 2019, 687: 218-231.

[24] Qian R, Peng FL, Xue K et al. Assessing the risks of harmful algal blooms accumulation at littoral zone of large lakes and reservoirs: An example from Lake Chaohu. J Lake Sci, 2022, 34(1). DOI: 10.18307/2022.0103. [ 钱瑞, 彭福利, 薛坤 等. 大型湖库滨岸带蓝藻水华堆积风险评估——巢湖为例. 湖泊科学, 2022, 34(1).] 